\title{
Water Quality Improvement after Establishing Seawater Exchange System at Jumunjin Harbor in Korea
}

\section{Sang-Ho Oh' 1 Dal Soo Lee ${ }^{1}$ Kwang Soo Lee ${ }^{1} \cdot$ Dong Jun Han' ${ }^{2}$ Chang II kim ${ }^{3}$ \\ 1 Korea Ocean Research \& Development Institiute (KORDI) \\ 2 Gangwon Provincial University ${ }^{3}{ }^{3}$ Yooshin Engineering Corporation}

\section{Introduction}

Environmental problems in Jumunjin harbor

Jumunjin : Located on the east coast of Korean peninsula

Narrow harbor mouth \& Closed waters

- Had suffered serious pollution problems in the past
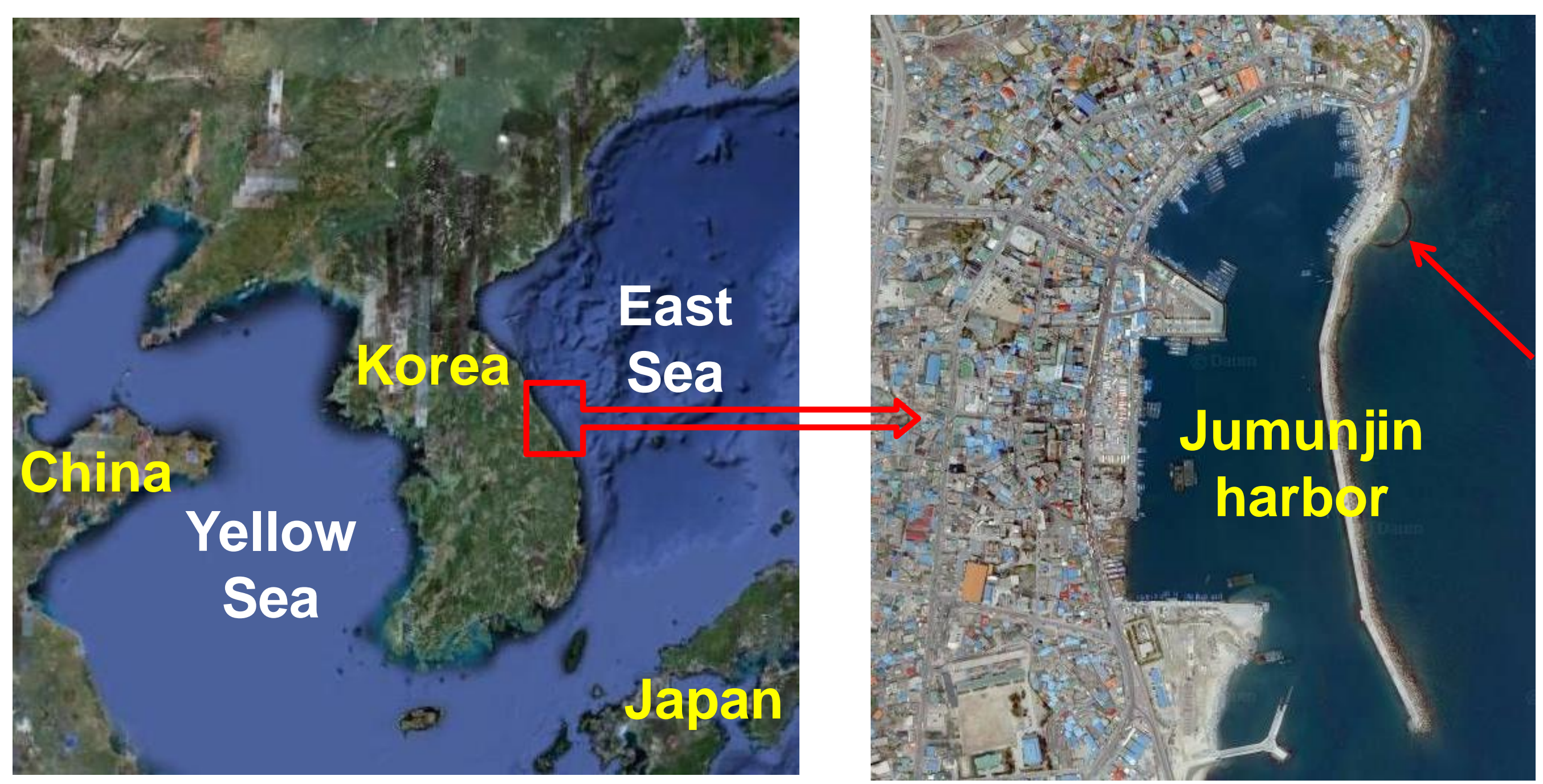

Seawater exchange system

Improvement of water quality

Water quality of Jumujin harbor has been greatly improved after establishing seawater exchange system

The results of water quality monitoring before, during, and after the construction of seawater exchange system are reported in this study

\section{Seawater Exchange System}

\section{General configuration}

- Consists of three seawater intake caissons and a detached semicircle seawall exterior to the preexisting breakwater

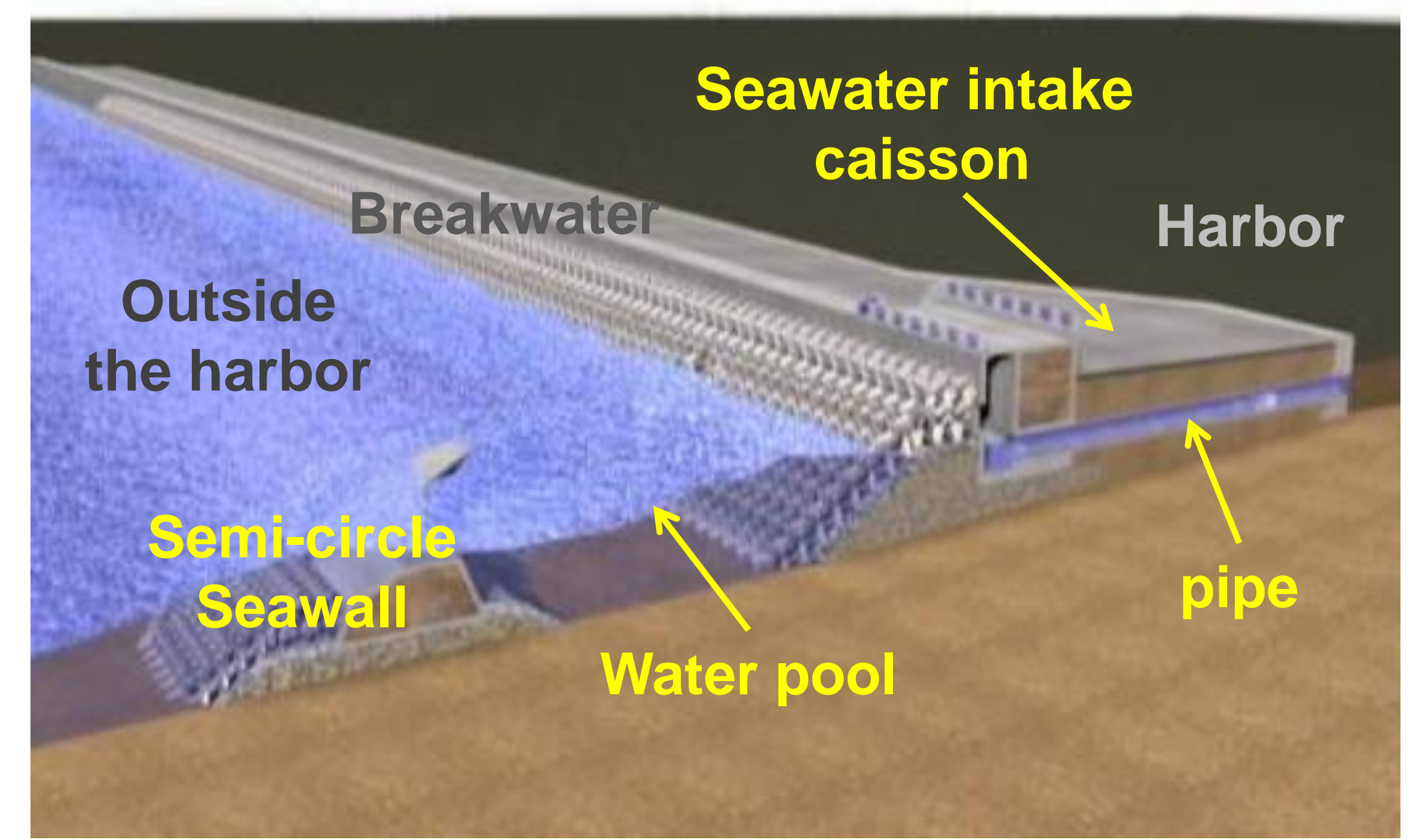

Perimeter of the semi-circle seawall : $110 \mathrm{~m}$

Width of each caisson : $8 \mathrm{~m}$ (Total width : $8 \mathrm{~m} @ 3=24 \mathrm{~m}$ )

Diameter of the pipe : $1.5 \mathrm{~m}$ (two pipes in each caisson)

Mean seawater level at water pool is maintained slightly higher than that inside harbor : forms unidirectional flows to the harbor

Construction of the seawater exchange system
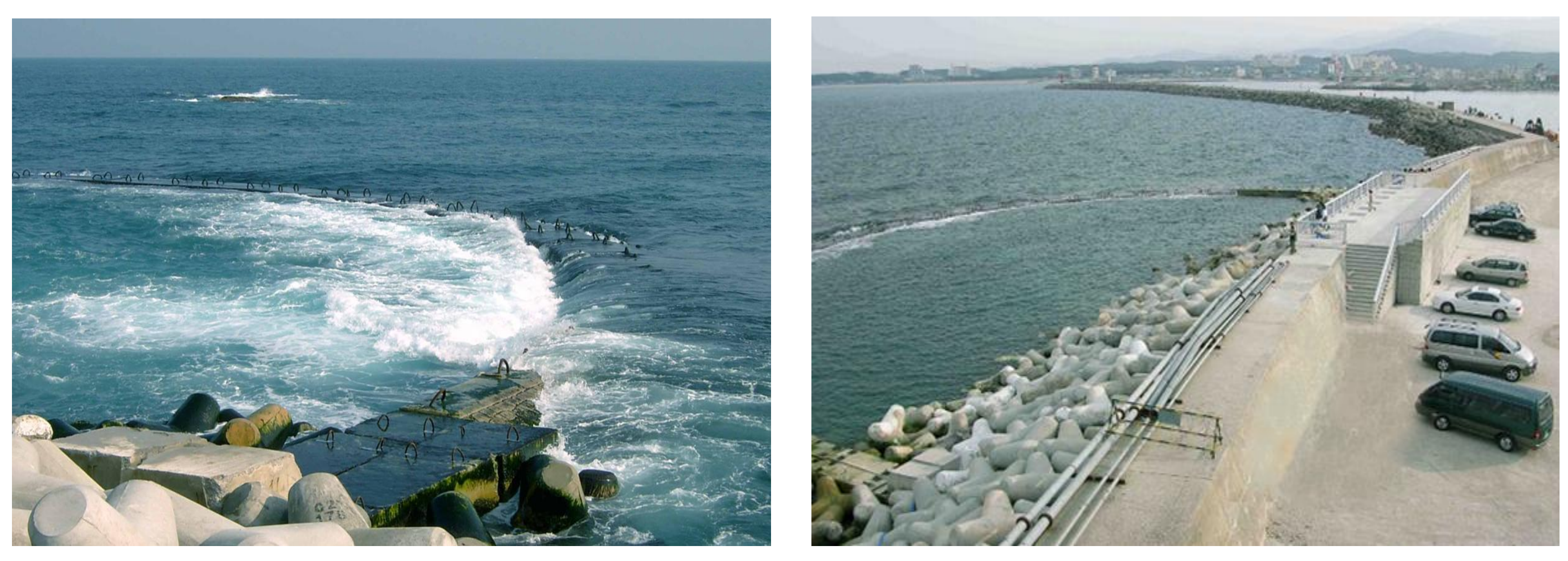

Accomplishment : Apr. 2004

Target intake volume : 1,000,000 $\mathrm{m}^{3} /$ week

Net circulation rate: $97 \%$ / 3 weeks

\section{Water Quality Monitoring}

Locations \& Parameters

15 sampling stations around the harbor (See right figure)

Categorized into three 'Zones'

\section{Monitoring period}

- Jan. 2002 Sep. 2007

Monitoring parameters

- 11 index parameters as follows

- Temperature, Salinity, ph, DO(Disolved Oxygen), SS(Suspended Solids), COD(Chemical Oxygen Demand), T-N(Total Nitrogen), T-P(Total

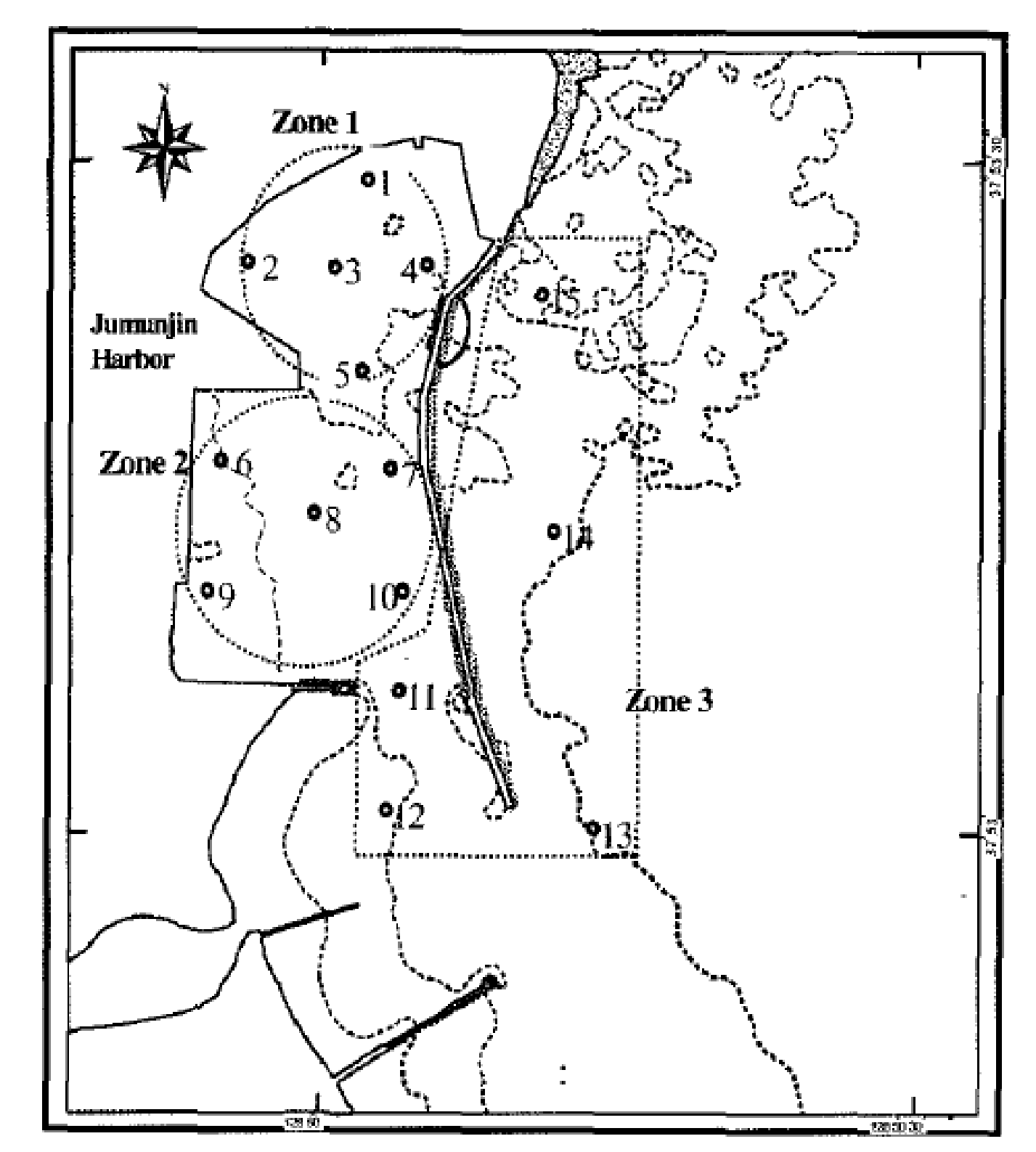

Results of monitoring

Water quality was dramatically improved after completion of the seawater exchange system

The improvement was most apparent in Zone 1 (See figures below), where water quality deterioration was the most serious in the past

Seasonal variation of parameters were found, which is ascribed to smaller waves (except during typhoon passage) and increase of eutrophication under high temperature in summer season
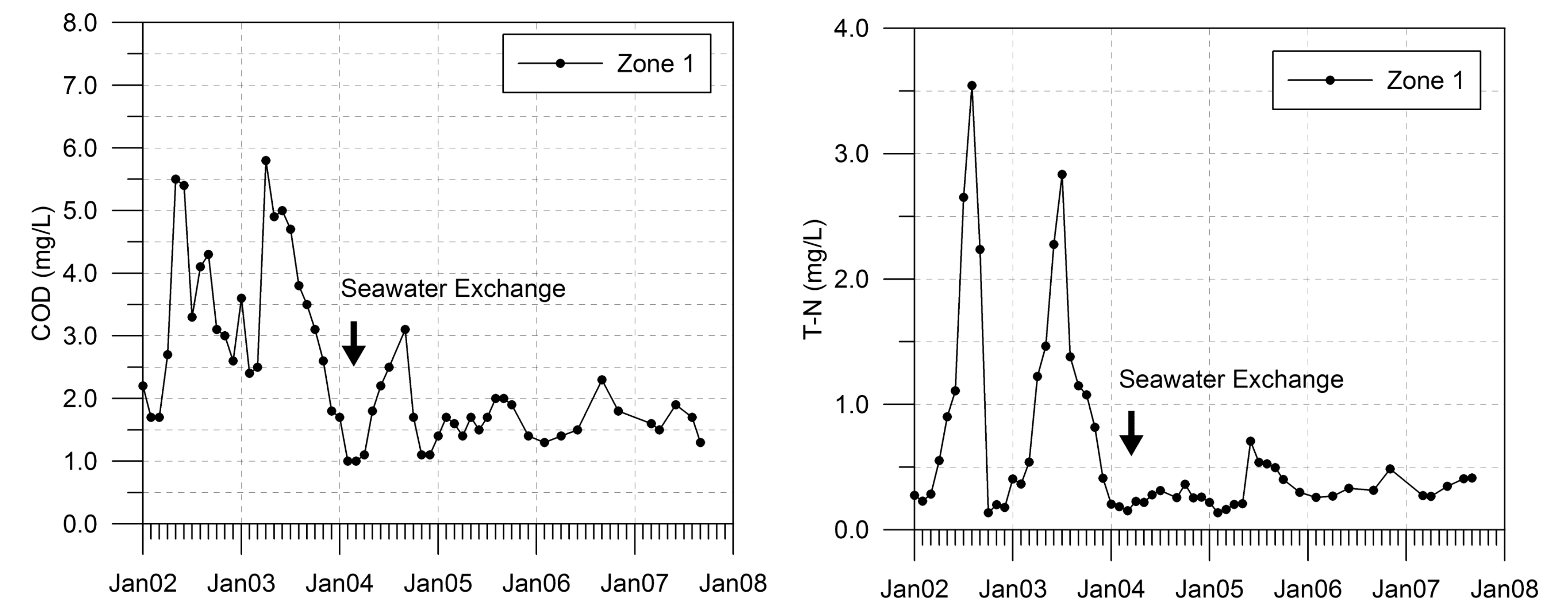

\section{Seawater Intake Volume}

Observation of intake volume

Besides the water quality monitoring, seawater intake volume through the pipes was also measured since 2005

On average, $3,729,800 \mathrm{~m}^{3} /$ month of seawater is estimated to be taken into the harbor, correspondent to the target intake volume $(1,000,000$ $\mathrm{m}^{3} /$ week) considered in the design of the structure

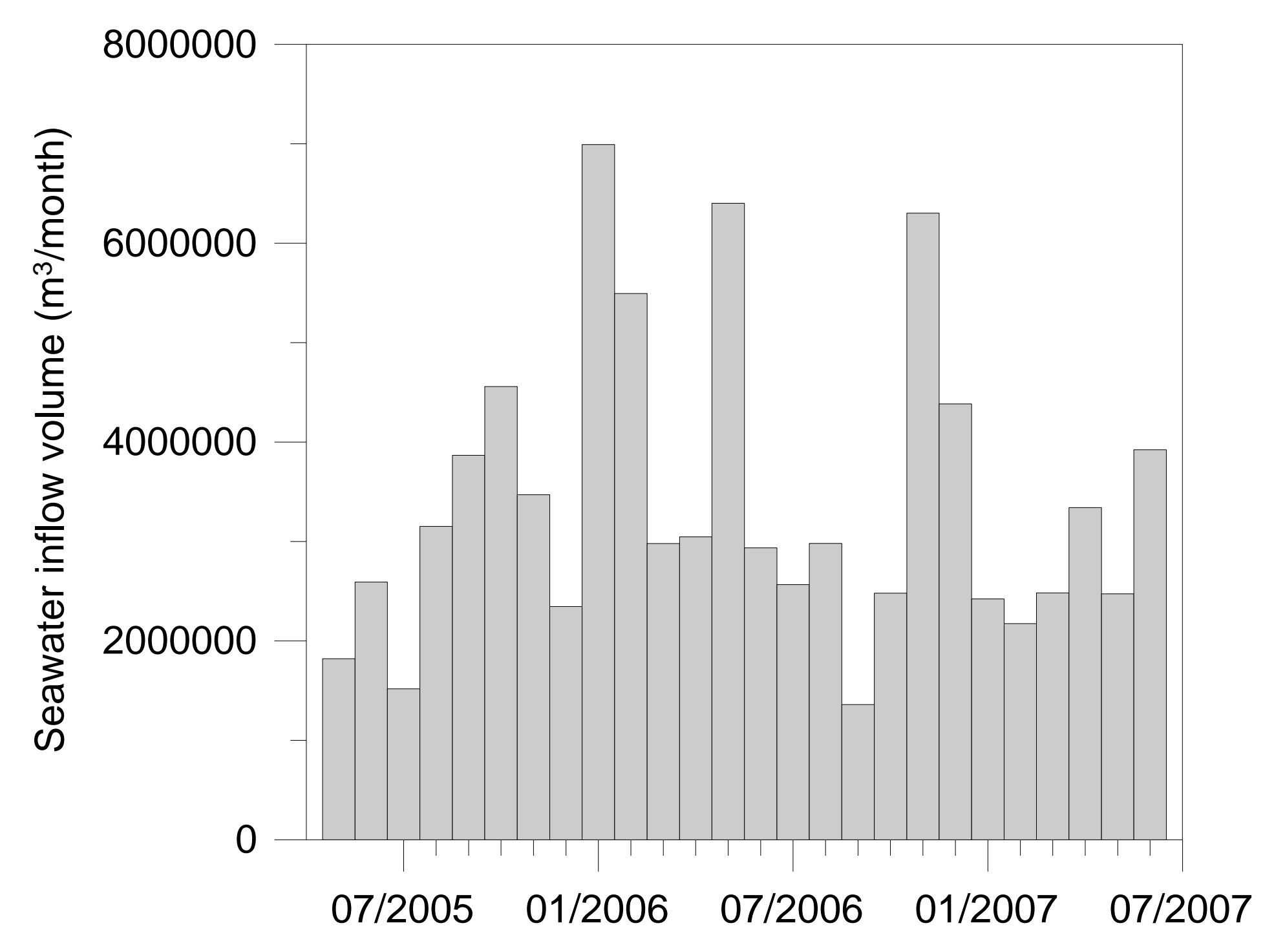

\section{Contact}

Korea Ocean Research \& Development Institute

Sang-Ho Oh (ohsangho@kordi.re.kr)

Dal Soo Lee (dslee@kordi.re.kr)

Kwang Soo Lee (kslee@kordi.re.kr) 